\title{
Response Strategies of the Creative Market Industry in the Post-Epidemic Era in Taiwan-Taking ISHANDS International Creative Market as an Example
}

\author{
Jui-Lung Chen ${ }^{1} \&$ Yu-Chia Chen ${ }^{1}$ \\ ${ }^{1}$ Department of Business Administration, National Chin-Yi University of Technology, Taiwan, R.O.C \\ Correspondence: Jui-Lung Chen, Department of Business Administration, National Chin-Yi University of \\ Technology, No.57, Sec. 2, Zhongshan Rd., Taiping Dist., Taichung 41170, Taiwan, R.O.C. E-mail: \\ leonchen@ncut.edu.tw
}

Received: July 24, 2021

Accepted: August 16, 2021

Online Published: August 25, 2021

doi:10.5539/ijbm.v16n9p144

URL: https://doi.org/10.5539/ijbm.v16n9p144

\begin{abstract}
The creative market is mainly composed of small and medium-sized and micro-sized enterprises. It focuses on personal creation, as well as face-to-face sales with customers in the market. Affected by COVID-19, customers no longer go out, and markets are canceled due to crowds, which affect the business of market curators, as well as cultural and creative brands. While the epidemic is still raging, how to respond and transform has become the key to survival. This research mainly focuses on comparing and analyzing the situation in 2019 and 2020 of "ISHANDS International Creative Market", which is a creative market regularly held, as well as seven cultural and creative brands participating in this creative market in Taiwan. Through on-site observation and in-depth interviews, it interviews with curators of the creative market and operators of market brands, analyzes the creation and development process and planning of the "ISHANDS International Creative Market", as well as key factors for cultural and creative brands to participate in creative markets, brand entrepreneurship and development, and difficulties they face at present. It sorts out the business interactions between the creative market and cultural and creative brands through case studies, summarizes them, and analyzes various interactions with business models, so as to understand the current situation of the creative market facing COVID-19 and possible future development in response. This research finds that: (1) the success of the creative market lies in brand differentiation and persistence; (2) the brand image building of the creative market and cultural and creative brands are key factors for each other; (3) the problems faced by the creative market under the influence of COVID-19; (4) it should accelerate the marketing and application of technologies in response to COVID-19; (5) it needs to master key resources in response to the post-epidemic era; (6) it explores the future development trend of Taiwan's creative market industry.
\end{abstract}

Keywords: post-epidemic, new crown pneumonia (COVID-19), creative market, cultural and creative brand

\section{Introduction}

Outbreaks such as MERS and COVID-19 have had a profound and widespread impact on societies and industries. The impact of the epidemic is especially felt by industries that require meeting customers face-to-face for some types of work and service. Taiwan's creative markets began to take shape in 1998 and then emerged in Nanhai Gallery in 2004, with the number reaching its peak in 2006. The creative markets were held just once every two or three weeks in 2007 due to the excessive proliferation of cultural and creative markets. However, so far in 2021, besides the five major cultural and creative parks in Taiwan, cultural centers and specific areas in counties and cities regularly hold cultural and creative markets every weekend, various events held from time to time and the government's activity projects, etc. also have the presence of cultural and creative markets as a call to customers. Even department stores have been holding creative markets recently, so it is clear that creative markets have a certain appeal to the public. According to 2018, 2019, and 2020 annual reports on the development of Taiwan's cultural and creative industries, $88.53 \%$ of the turnover of Taiwan's cultural and creative industries came from domestic sales, but from 2013 to 2020 it has been declining and the growth is already negative, especially in the craft industry, which accounts for $60 \%$ of the overall decline in turnover of the cultural and creative industries (Department of Statistics, Ministry of Culture R.O.C., 2021). For consumers, the variety of products, the theme of the event, the understanding of the characteristics of the creative market, and 
the promotion are generally very important. Therefore, this study will explore the organization of creative market, cultural and creative brands, and the key to the future development from these three perspectives through field observations and in-depth interviews.

In the last decade, Taiwan has been following the trend of cultural and creative activities in Japan, which have been inspired by the two famous cultural and creative markets in Japan, CREAM and HandMade in Japan Fes. In this trend, creative markets and individual creative handicrafts are preferred by young people to start their own businesses. However, most of the handicraft creators' businesses are micro-entrepreneurship, and they can only earn revenue and gain popularity by participating in creative markets in Taiwan, and because the unstable quality of creative markets varies and the selection of products by the market organizers is unstable, both entrepreneurs and organizers find it difficult to organize creative markets, not to mention promoting Taiwan's handicraft design and creativity abroad. Therefore, we would like to find a business model that allows handicraft entrepreneurs to find an opportunity with minimal opportunity cost, which can address business problems, investment of venture capital and other capital, and business-related problems; and create a more effective sales channel to find a way out for the reinvigoration of various cultural and creative parks or mosquito halls (unused public buildings). From the end of 2019 to 2020, many creative markets have been closed down due to COVID-19, and the whole creative bazaar industry has shrunk due to customers' reluctance to attend events in crowded places. Therefore, it is hoped that this study will find out how to create successful creative markets in the post-epidemic era, so as to help more creative brands to create awareness and profits. COVID-19, the black swan of the market in the spring of 2020, has forced many countries around the world to seal off their cities and lock down their countries due to the sudden epidemic, and both the anti-epidemic measures and the panic brought by the epidemic have had a huge impact on the global market and people's consumption behavior. In the post-epidemic era, various sectors of society have begun to pay attention to and discuss the impact of the epidemic, the changes to the economic structure, daily life, and consumption patterns, and which patterns will become the new norm after the epidemic. This study examines the future trends of Taiwan's creative markets in the post-epidemic era. Creative markets provide channels for creators of creative brands to publish their works and generate about $60 \%$ of their revenue, ranging from booths in creative markets, consignment sales in physical stores, and sales on online platforms to the enhancement of brand business value. Especially under the influence of the epidemic, they are in the stage of transformation and adaptation, and at the same time, they are facing the problems of easy copying and imitation of creative ideas and high similarity of goods after transformation; while the curators of creative markets face the challenges of screening creative brands, how to prevent similar goods of inferior quality from emerging on Taobao and online wholesale channels, and finding their market positioning and complementary creative brands in many creative markets. Therefore, in addition to constantly introducing new ideas and combining the brand with the venue, establishing a distinctive brand style of the creative market is the main key factor for a creative market to stand out and establish a reputation in the whole market.

In this study, we have found that through the many cultural and creative markets held by ISHANDS, the ISHANDS International Creative Market has gradually developed distinctive brands of cultural and creative markets by operating and coaching creative brands in response to the impact of the epidemic. Therefore, the purpose of this study is to (1) find out the development opportunities of creative brands through in-depth interviews with creative brand entrepreneurs and serve as a reference for future brand entrepreneurs; (2) explore the internal customer relationship and industrial interaction of the creative market, and the success factors of operation. (3) explore the development of creative marketplaces before and after the epidemic and the solutions; (4) take ISHANDS International Creative Market as an example to explore the development direction of the creative market after the epidemic; (5) serve as a reference for the government's subsidy support for the epidemic and the subsequent development of cultural and creative industries.

\section{Literature Review}

\subsection{Post-Epidemic Era}

As the vaccine is available and the epidemic is under control, we are moving into the post-epidemic era. In Taiwan, the epidemic was under control from January to June 2020, so the control was slightly relaxed after June 2020. From March 2020 to December 23, 2020, Taiwan was free of indigenous infections for 283 days, the longest period in the world, which contributed to Taiwan's economic development. After June 2020, Taiwan entered the post-epidemic era in a broad sense. Although there was another wave of local outbreaks at the end of May 2021 and the country was put on alert level 3, Taiwan gradually lifted the lockdown after July when the outbreak was under control and the vaccine was administered in batches. However, new COVID-19 cases spiked in some countries around the world. In response to the impact of COVID-19 on the economy and consumer behavior of the entire population, the Executive Yuan and various ministries in Taiwan are working together with 
the Central Epidemic Command Center on the principle of "prevention first, relief second, and revitalization third" to prevent the epidemic. The measures related to the creative market industry are summarized in Table 1.

The Ministry of Culture of Taiwan announced the Relief and Economic Stimulus Package for Industry and Business with Operating Difficulties Due to the Effect of COVID-19 to make joint efforts with the arts and culture industry, business and related employees who have experienced operating challenges due to the effect of COVID-19 to overcome the difficulties. Businesses affected by the epidemic that operate or are engaged in the "operation and sale of publishing businesses and physical bookstores", "creation, research and development, exhibition and sale of visual arts, performing arts and crafts", "film screenings, film and television productions and popular music performances", "operation and sale of museums, local cultural centers, and community buildings", and "promotion and operation of tangible and intangible cultural assets" in Taiwan (The businesses referred to herein are legal entities, unincorporated bodies or firms, registered or incorporated in Taiwan) and natural persons with Taiwanese nationality whose contracts or other similar contracts are affected by the impact of the epidemic may apply for such relief in accordance with this announcement. The categories and scope of Art Fun Vouchers are as follows: (1) Arts and cultural venues and music performance spaces: applicable to various arts and cultural activities, including other arts and cultural venues: cultural and creative parks, clusters, exhibitions, and markets that mainly provide cultural and creative products or services; (2) Bookstores, record shops and musical instrument shops; (3) Movie theaters; (4) Advance tickets for arts and cultural performances; (5) Arts and cultural businesses, groups or workers. (Ministry of Culture R.O.C., 2021). Studies of the post-epidemic era in terms of industrial and economic trends, digital economy transition, and psychosocial impacts. As the epidemic affects all aspects of life, production, and economy, and the post-epidemic era is still short, there is little relevant study or literature on post-epidemic trends in industry and economics, digital economy transition, and psychosocial impacts, but future studies and literature should spring up like mushrooms. Creative Bazaar in Taiwan.

Table 1. Taiwan executive yuan and various ministries' subsidies related to cultural and creative industries

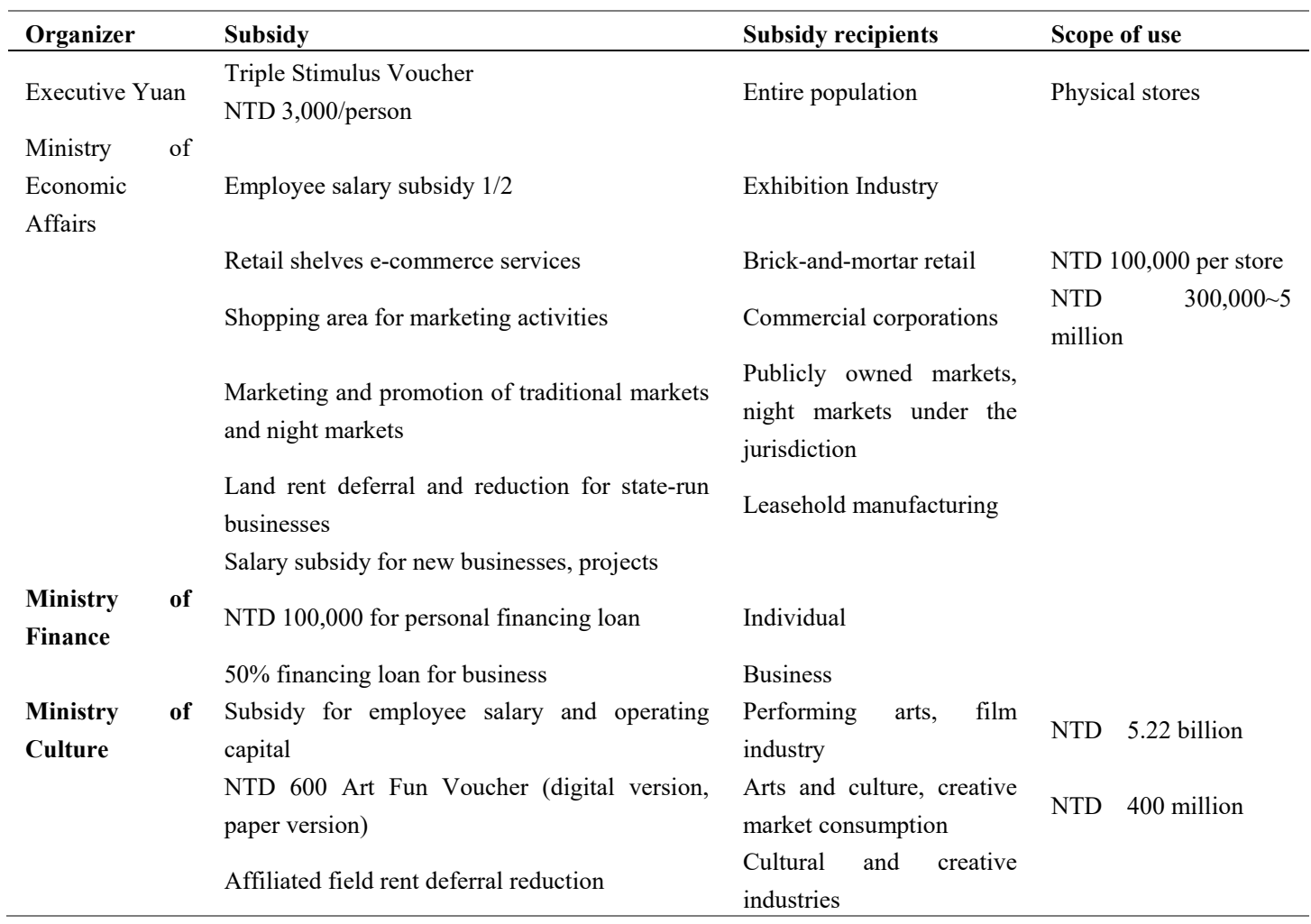

\subsection{Creative Markets in Taiwan}

Creative markets are not only a part of local people's leisure life, but also a starting point for many artists and designers (Wang, 2004). Creative markets in Taiwan originated in around 2002 from the Guling Street Books \& Creative Bazaar held by Nanhai Gallery in conjunction with the neighboring communities, but at that time the 
Guling Street Books \& Creative Bazaar was not the so-called creative market, but a simple second-hand bookstall. However, due to this event, the creative bazaar in Taiwan gradually sprouted, and only in 2005 did the CAMPO Life Art Carnival meet the definition of a creative bazaar. Nowadays, many of the organizers of creative bazaars are from the preparatory staff of CAMPO, so we can consider CAMPO as the beginning of creative bazaars in Taiwan. Creative bazaars have their unique features, especially "creative people and creative works", which are musts for a creative bazaar. This unique charm has created a new cultural and creative force in Taiwan (Lee, 2009). Creativity encompasses everything in the world and is more profound than the word "art" (Soule, 2017). Creators can combine their creativity and innovation through creative bazaars, in which they can express themselves, with a special emphasis on culture, art, and design in the products they design. Today's creative bazaars are intended to give young people or entrepreneurs who want to create a chance to fulfill their dreams of becoming a stall owner, and to meet friends, meet fans and showcase their creative works in a place where they do not need to pay high rental prices, but only need to pay a small amount of rent to set up a stall in a legal place or even for free. Taiwan's creative bazaar is not just like the flea markets abroad, the site is also set up with lectures, mini-concerts, street performances, etc. It is like a carnival, and sometimes the theme changes every time due to current events. All over the world, there is a wave of creative bazaars, but the style varies, and Taiwan's creative bazaars put more emphasis on originality and handmade.

The initial slogan of the "cultural and creative industry" concept proposed in Taiwan is "industrialization of culture, industrial culture". "Culture" is a lifestyle, while "industry" is a production and marketing mode, and the connection point between the two is "creativity" (Pan, 2015). Consumption is not only an economic activity but also a social and cultural act. The consumption habits of young people in an era can reveal contemporary economic, cultural, and consumer values. Most of the products in the creative markets are non-essential goods, with emphasis on design and feelings. Creative bazaars bring a "lifestyle with experience value" because of the emotional temperature of handmade products, the sincere experience of the uniqueness of products, and the atmosphere created by the bazaar environment (music, performance, creative vendors, direct interaction between creators and consumers) create a highly experiential consumer behavior. The rise of the creative market can be said to be another wave of self-individualization in today's highly homogenized and reproduced products. Due to the rapid development of creative bazaars, attention should be paid to strengthening their inner creativity and characteristics, and if the quality of products cannot keep up with the speed of development, they will soon be a mere formality and become a bubble. Creative bazaars are not purely commercial but include a high degree of creativity and vitality to satisfy the creators' desire to create and their sense of accomplishment, as well as to satisfy consumers' needs to pursue their unique style (Luo, 2008). Creative bazaars are already a very popular and even mature industry in Taiwan, but the turnover began to decline in 2013, which shows that consumers' willingness to buy in creative bazaars has gradually decreased. To make people willing to spend money to support Taiwan's creative industries, several things need to be discussed: (1) Improve the problem of existing creative bazaar products being too similar or identical or including wholesale goods; (2) Improve the confusing pricing of the existing creative goods; (3) Whether the characteristics of the bazaar can attract consumers; (4) Effective promotion to make the creative bazaar known to more people (Zhang et al., 2019).

Through the relevant literature in Taiwan, we found that many of the papers are looking at creative bazaars in Taiwan from the perspective of art curators, and there is a lack of interaction between creative bazaars and inner customers. Commercial and consumer behavior is a very important condition, even a necessary condition, for cultural growth. Culture and art have so-called "functional value" and "symbolic value", and for the cultural industry, the main purpose is to promote "functional value", including beautifying the home living environment, providing leisure and entertainment, boosting the economy, and bringing jobs, and providing entrepreneurship opportunities (Pan, 2015). The literature on creative bazaars in Taiwan is most abundant between 2006 and 2008, but relatively less after 2010, which is quite related to the rise and fall of creative bazaars. The other type of literature studies is mainly from design colleges and art colleges, looking at creative bazaars or cultural and creative fairs in Taiwan from the perspective of art curation. Over the past decade, major developed countries including Europe, America, Japan, Korea, and Asia have realized the enormous energy of economic growth and industrial upgrading that the emerging cultural and creative industries can bring, and each country has included the development of cultural and creative industries in a major national development plan. Taiwan's cultural and creative industries are currently dominated by the domestic market, with domestic sales accounting for approximately $90 \%$ of total turnover in recent years, and the music and performing arts industries showed the highest growth rates (Department of Statistics, Ministry of Culture R.O.C., 2021). In recent years, cultural and creative bazaars have been booming, but less study has been conducted on the success factors of bazaar curation as the characteristics of bazaars. The discussion of the bazaar services and characteristics required by brands participating in cultural and creative bazaars and the factors influencing brand selection will be helpful to 
Taiwan's bazaar brand management and scale development and will promote the development of cultural and creative industry policies.

\subsection{Taiwan's Cultural and Creative Park}

In the creative market industry chain, apart from virtual network sales, a venue is needed to hold a creative market. In this study, the term "cultural and creative park" refers to the management of the indoor space of the venue that can provide services. Open-air creative bazaars, which are generally held in open spaces such as parks or vacant lots and are handled by the organizers themselves, are not included in the scope of this study. The term "cultural and creative" has been booming in recent years, and cultural and creative parks and venues have sprung up all over Taiwan, with a conservative estimate of about 30 government and private parks and an increasing number of local cultural centers in counties and cities, not including outdoor venues such as parks and green areas.

\subsection{Cultural and Creative Brands}

The term "brand" refers to the symbol of a product or service. A symbolic identifier, on the other hand, is a "trademark". The domain covered by a brand must include goodwill, product, corporate culture, and overall management of operations (Kotler and Armstrong, 2017). Thus, a brand is not a symbol, but the combination of a company's overall competition, or corporate competitiveness. In the past literature, it was generally agreed that brand building is an important key to the operation of cultural and creative businesses (Wang, 2014). However, the need for branding in the cultural and creative industries is due to the fact that cultural creativity is diverse, and creative products are not brands per se, and each product launched is not related to the other, so branding is needed to link consumers' memories and perceptions. Creativity is not a precise concept, but sometimes refers to a process or a product or result; Creativity and Creatives (artistic and cultural); or the talent of the creator. Creativity can be thought of as the skill to create products that are highly applicable, entertaining, or aesthetically pleasing, or as the talent to create interesting things. In this way of thinking, creativity is not so much skill or knowledge as it is a by-product of a variety of special skills, such as writing, painting, craftsmanship, or playing a musical instrument. On the other hand, a creator is a person who expresses the original idea in various forms. In the context of the creative industry as a whole, creators are those who invent, create and use various media to express their ideas, from novelists to musicians, architects and graphic designers, and craft artists. Creative brands are built based on goods or services that derive from one's creativity, skills, and talents and are able to create wealth through the formation and use of the intellectual property (Davies and Sigthorsson, 2013). Creative brands include creativity and skills, and handicrafts are popular among modern people. With the increase of spending power, people are no longer only pursuing material enjoyment, but also spiritual and personalized needs satisfaction. The handicrafts creation has been generally accepted by the general public, and the trend and effect derived from it in the creative markets also reflect the importance people attach to handcrafted, hand-oriented design. In recent years, the development of creative handicrafts has incorporated the concept of experience, that is, using the body as the basis for receiving creative perceptions and forming consciousness, which is also the result of the projection of the trend of thought and art forms over the generations (Chou, 2009). Most of the creative brands in this study are incubating brands that communicate their creative connotations and values to consumers through products, services, contacts, and promotion in creative markets. Establishing a creative brand can help deepen the impression of creative products and services in consumers' minds and identify the appropriate target group, which is also the purpose of many initial creative brands to participate in the market.

\section{Methodology}

This study adopts the qualitative case study methodology, mainly through interviews and observations supplemented by documentary analysis. Through case studies and in-depth interviews, this study was aimed to explore the role of creative market organizers, the interaction of creative brands and demands, and the assistance of local venues in the international creative market industry organized in the case. We collected data and interviewed relevant operators, summarized the data and analyzed the interaction of market operation, and categorized the actions and responses of the international creative market held in each case before and after the epidemic. The post-epidemic era refers to the period when effective vaccines were available, or the epidemic could be slightly controlled after severe human-to-human transmission of COVID-19 occurred in January 2020. This study examines the impact on creative markets and creative brands and their response strategies in the post-epidemic period when border control and assembly restrictions are slightly relaxed. The creative markets referred to in this study are limited to creative markets with the participation of creative brands and handicraft designers, etc., which has existed continuously for more than three years, especially these starting before 2018 
and still existing in 2020, and the ISHANDS international creative market is used as the case in this study.

\subsection{Research Methods and Tools}

This study used qualitative research as the research method, which refers to a study that uses interviews, participant observation, and documentary data collection to analyze and interpret various phenomena in society (Patton, 2002). In addition, this study adopts a qualitative case study method which is mainly conducted by in-depth interviews, observations, and documentary analysis, on a case-by-case basis. A case study is a methodological approach to identify the problem and find the solution to it by applying the methodological techniques to the particular problem. The analysis of a particular case is not conducted on many individuals at the same time. The subject of a case study may be an individual, a family, an institution, a group, a community, a region, or a country (Chen, 1995). Eisenhardt (1989) argued that the case study approach is focused on the study of dynamic states in a single context and is also particularly suitable for new subject areas. He argued that the case study approach is based on multiple database links, comparisons, analyses, and generalizations, and that the sources of these data are integrated with practice, and the conclusions and hypotheses inferred from them are more feasible. However, as the data may be too complex, the theoretical results obtained may not be easily understood by others in terms of content and meaning.

An in-depth interview is a conversation between two or more people, which consists of at least one interviewer and one or more interviewees. The interviewer obtains some information about the interviewee through verbal communication, i.e., like a conversation, the interviewer collects the information and data he or she needs in the process of asking and answering questions. The interview is a means of gathering information, and if it is properly controlled and organized, the interviewer can probe the other person's mind and get the desired answer or message. In addition, interviews can be formal or informal and can be structured, unstructured, or semi-structured. In short, they are simply non-standard, unstructured, or open-ended questions that get to the heart of the matter from the periphery. Structured interviews are highly controlled interviews, sort of like a questionnaire; and semi-structured interviews are somewhere in between, taking into account the creator's experience, diversity, and variability, which are preferred in this study to facilitate control of the questions and to allow respondents to give their own opinions without being limited by the content of the questions (Yuan, 2002). In-depth interviewing refers to the desire to obtain important factors that cannot be obtained through face-to-face interviews alone (Wen and Yang, 2000). In-depth interviews are different from simple interviews in that they are designed to provide insight into the true nature of the interview, its meaning, impact, future development, and solutions. Generally, in-depth interviews are more time-consuming than general interviews, and the results are more in-depth in describing the essence of things for further analysis.

Observation is the systematic documentation of a problem observed over time. In addition to observing the behavior of the subject, it is more important to understand the meaning of the behavior, its interaction with the environment, and other targets. To understand the meaning of the behavior, participant observation can be used. The advantages of observational research are that it is integrated into the context of the study and the information is realistic, in-depth, and humanistic, but there are also disadvantages if the research process is not rigorous enough (Wu, 2015). Document Analysis refers to the method of collecting data from research reports, industry dynamics, market information, etc., according to the research purpose or topic, in order to accurately grasp the problem to be studied. The collected content should be as comprehensive, rich, and extensive as possible, and the collected data should be collated and consolidated to analyze the origin, background, causes, impact, and significance of the event. The documentary data can be government reports, statistical data, industrial and commercial research, documentary record databases, corporate organization data, library books, papers and journals, newspaper news, etc. (Herzog, 1996). This study will collect the relevant laws and regulations on the cultural and creative industries in Taiwan, statistics before and after the epidemic, research literature on relevant research topics and research objectives, and compare the expectations, options, and demands of the respondents for cultural and creative bazaars to understand the trends and dilemmas of the development of cultural and creative bazaars, the industrial relationship between the bazaar organizers and the participating cultural and creative brands and cultural and creative parks (venues), and the various responses to the post-epidemic era, their effectiveness, and the government's counseling measures. This study would then move on to the development of the cultural and creative market industry in the post-epidemic period and the related regulatory proposals. The data collected include domestic and international news, papers, journals, research reports, government-related research reports and publications, books, web pages, and reports of the Legislative Yuan.

\subsection{Case Introduction}

ISHANDS was established by Astrella Co., Ltd., which is mainly engaged in international trade and assists Japanese trading partners to promote creative brands and introduce them to creative markets in Taiwan based on 
the trading relationship with Japanese customers. Founded by four founders in 2017, ISHANDS is engaged in creative bazaars and cultural and creative industry promotion-related business. It also cooperates with ACE Japan, Indigo Inc, Hong Kong Creative, ART Singapore, and other overseas licensed IPs. Through ACE, ISHANDS has overseas offices in New York, Tokyo, Fukuoka, Hong Kong, and Malaysia to connect with overseas cultural entrepreneurs and curatorial resources and invite famous foreign writers, movie stars, illustrators, etc. Authorized foreign instructors, course certification, and other added values distinguish it from other creative bazaars in Taiwan. ISHANDS also brings in brands from Japan that are interested in opening stores overseas to set up pop-up stores and stalls in creative markets in Taiwan to see the market acceptance and gather customers for the mall. ISHANDS also plans customer shows and exhibitions to attract attention and bring in box office sales. Over the years, ISHANDS has organized more than 20 bazaars and 2 international exhibitions each year, with 323,680 visitors in the past year. The actual revenue generated reached about NTD $20,407,880,2,880$ jobs were created, and 23,280 people participated in seminars. About 3,800 groups of Taiwanese handicraft creative brands have joined the group, and 2,821 creative brands have participated in ISHANDS creative markets, including 322 brands from foreign countries and regions including Japan, Hong Kong, Malaysia, Thailand, Singapore, South Korea, Australia, Russia, etc.

\section{Interview Analysis and Results}

This study adopted a "semi-structured" interview for in-depth interviews, which is easier to control the core of the questions and to collate while not influencing the completeness of the interviewees' answers. Nine interviews were conducted with the following respondents: A-1 Brand: ISHANDS International Creative Product Market, Interviewee of Ms. Chang (person in charge) and Mr. Lin; M-1 Brand: STRING MAN, Interviewee of Mr. Shen (the creator and owner of the brand); M-2 Brand: Ren Jhong Ren Corp., Interviewee of Mr. Wen (the creator and person in charge); M-3 Brand: Yoyo hand, Interviewee of Ms. Chang (the brand designer and person in charge); M-4 Brand: January $1^{\text {st }}$, Interviewee of Ms. Lai (the brand designer and person in charge); M-5 Brand: Lighthouse, Interviewee of Ms. Wang (the brand designer and person in charge); M-6 Brand: NICON, Interviewee of Mr. Huang (the person in charge and industrial arts teacher); M-7 Brand: CHANCE, Interviewee of Mr. Chen (the founder and baking master of the brand); S-1 Brand: 1914Huashan 1914 Creative Park, Interviewee of Ms. Yang (the activity leader of the park). The analysis and results of the interviews are as follows.

\subsection{ISHANDS International Creative Market}

The success factors of ISHANDS International Creative Market, the principles of selecting creative brands, the impact of the epidemic, and the response strategies in the post-epidemic era are summarized in Tables $2 \sim 5$.

Table 2. Success factors of ISHANDS international creative market

\begin{tabular}{|c|c|c|}
\hline Item & Principle & Description \\
\hline 1 & Uniqueness & $\begin{array}{l}\text { Most creators go to Taiwan in overseas exhibitions, which forms a competitive } \\
\text { threshold. Taiwan's famous creative brands selectively participate in the } \\
\text { creative market every year, forming pop-up stores. }\end{array}$ \\
\hline 2 & Service power of the industry & $\begin{array}{l}\text { The company is an international trading company and can provide consultation } \\
\text { and agency services for overseas brands that come to Taiwan to participate in } \\
\text { the market. }\end{array}$ \\
\hline 3 & Word of mouth publicity & $\begin{array}{l}\text { Since } 2017 \text {, the market has been free to enter to allow the public to know the } \\
\text { content of the creative market, and since } 2018 \text {, it has gradually built up a good } \\
\text { reputation and become a kind of expectation and cultural inertia. }\end{array}$ \\
\hline 4 & Venue & $\begin{array}{l}\text { The location at Huashan } 1914 \text { Creative Park brings transportation convenience } \\
\text { and facilitates a gathering of the target audience for cultural and creative } \\
\text { industries; the indoor venue is comfortable and rich in history and culture. }\end{array}$ \\
\hline 5 & Exhibition planning & $\begin{array}{l}\text { The exhibition space and the marketplace atmosphere are well set up so that } \\
\text { the exhibiting brands and visitors can feel the atmosphere of creative markets } \\
\text { and shopping. }\end{array}$ \\
\hline 6 & Ticketing & $\begin{array}{l}\text { The target group is identified in advance, and some customers are filtered out, } \\
\text { so that those who really want to shop and buy can be better served. } \\
\text { Because of the ticketed admission, it is easier to promote the purchase, } \\
\text { creating a good cycle of the market and encouraging the creation of creative } \\
\text { brands. }\end{array}$ \\
\hline
\end{tabular}


Table 3. ISHANDS market's principles for selecting creative brands

\begin{tabular}{lll}
\hline Item & Principle & Description \\
\hline 1 & Originality & $\begin{array}{l}\text { The creative market gives top priority to creativity, innovation, respect for } \\
\text { intellectual property rights, and there shall be no plagiarism, Taobao wholesale } \\
\text { goods, etc. }\end{array}$ \\
2 & Brand development integrity & $\begin{array}{l}\text { Complete goods portfolio, special display performance } \\
\text { Overlap of product categories that the organizer will not allow too many similar } \\
\text { products to avoid competition and increase the richness of the bazaar. The } \\
\text { categories can be found in Table 3-4 ISHANDS classification. }\end{array}$ \\
3 & Uniqueness & Impressions are important, whether the participant complies with the rules and \\
& Past cooperation experience \\
& & $\begin{array}{l}\text { International creative markets require a higher level of integrity and brand } \\
\text { maturity; } \\
\text { Local markets are open to newcomers. }\end{array}$ \\
& Rank of the market &
\end{tabular}

Table 4. Impact of the epidemic

\begin{tabular}{|c|c|c|}
\hline Item & Principle & Description \\
\hline 1 & Market sessions & $\begin{array}{l}\text { From the beginning of the epidemic in January } 2020 \text { to October of the same year, } \\
\text { a total of six bazaars were canceled, including the } 2020 \text { Japanese Craftsmen's } \\
\text { Handicrafts Creative Bazaar. }\end{array}$ \\
\hline 2 & Uniqueness disappeared & $\begin{array}{l}\text { The staff and creators of overseas creative brands were unable to come to Taiwan } \\
\text { for exchanges. }\end{array}$ \\
\hline 3 & development & $\begin{array}{l}\text { Originally scheduled to exhibit Taiwan's creative brands abroad but canceled due } \\
\text { to the epidemic. }\end{array}$ \\
\hline 4 & Past cooperation experience & $\begin{array}{l}\text { Based on past cooperation and friendship built, some creative brands were } \\
\text { supported to set up stalls. }\end{array}$ \\
\hline 5 & Impact on income & $\begin{array}{l}\text { Generally, the Taiwan creative markets have been able to break even and were not } \\
\text { greatly affected by the epidemic. }\end{array}$ \\
\hline
\end{tabular}

Table 5. Response strategies in the post-epidemic era

\begin{tabular}{|c|c|c|}
\hline Item & Principle & Description \\
\hline 1 & $\begin{array}{l}\text { Accelerate the use of online } \\
\text { technology }\end{array}$ & $\begin{array}{l}\text { Use of non-contact technology, such as online payment, cell phone } \mathrm{fb} \\
\text { identification admission registration, etc. } \\
\text { Overseas creators talk and communicate with consumers through live } \\
\text { streaming. } \\
\text { Accelerate the establishment of online shopping platforms to respond to the } \\
\text { stay-at-home economy in the post-epidemic era. } \\
\text { Use of remote technology, such as face painting, which can be drawn from } \\
\text { remote locations and printed in Taiwan. }\end{array}$ \\
\hline 2 & $\begin{array}{l}\text { Expand consignment sales in } \\
\text { pop-up stores }\end{array}$ & $\begin{array}{l}\text { Creative brand creators consign their products to stores to reduce the number of } \\
\text { people they reach and increase their income. }\end{array}$ \\
\hline 3 & $\begin{array}{l}\text { Facilitate the experience } \\
\text { economy }\end{array}$ & $\begin{array}{l}\text { The handicraft workshop is a great place to experience doing things yourself } \\
\text { without having to spend time with unfamiliar people. } \\
\text { Reservation of time and place, exclusive teaching service }\end{array}$ \\
\hline 4 & Introduce foreign works & $\begin{array}{l}\text { Continuously introduce new products from abroad to maintain attention and } \\
\text { uniqueness, differentiation }\end{array}$ \\
\hline
\end{tabular}

\subsection{Huashan 1914 Creative Park}

The success factors of Huashan 1914 Creative Park, the selection principles, the impact of the epidemic and the response strategies in the post-epidemic era are summarized in Tables 6 to 9 . 
Table 6. Success factors of Huashan 1914 Creative Park

\begin{tabular}{lll}
\hline Item & Principle & Description \\
\hline 1 & Uniqueness & $\begin{array}{l}\text { It is the preferred venue for many events, and the Park and the exhibition and store } \\
\text { will drive traffic to each other. }\end{array}$ \\
& It is a historical and cultural building, which adds to the cultural atmosphere. \\
& Insist on cultural innovation to promote activities. \\
& High capital adequacy enables different experiments.
\end{tabular}

Table 7. Huashan 1914 creative park's principles for selecting exhibitions and events

\begin{tabular}{|c|c|c|}
\hline Item & Principle & Description \\
\hline 1 & Uniqueness & $\begin{array}{l}\text { The Park hopes that each event will have its characteristics and avoid too much } \\
\text { similarity to create a diverse development of the Park. }\end{array}$ \\
\hline 2 & Past cooperation experience & $\begin{array}{l}\text { The impression is important, and the level of curation needs to be evaluated and } \\
\text { recognized. }\end{array}$ \\
\hline 3 & Cultivating brands & $\begin{array}{l}\text { Identify creative brands that can be nurtured and coach them to set up stores in the } \\
\text { Park. }\end{array}$ \\
\hline
\end{tabular}

Table 8. Impact of the epidemic on Huashan 1914 Creative Park

\begin{tabular}{|c|c|c|}
\hline Item & Principle & Description \\
\hline 1 & $\begin{array}{l}\text { Cancellation of exhibition } \\
\text { venues }\end{array}$ & $\begin{array}{l}\text { Overseas exhibitions were not available. } \\
\text { Large-scale exhibitions were canceled due to the epidemic prevention policy. }\end{array}$ \\
\hline 2 & Fewer foreign tourists & $\begin{array}{l}\text { Due to the epidemic, foreign tourists were still unable to come to Taiwan, which } \\
\text { affected the number of visitors to the Park and decreased the turnover of stores } \\
\text { and restaurants in the Park. }\end{array}$ \\
\hline 3 & Decrease in revenue & $\begin{array}{l}\text { In order to support the stores in the park and tide over the difficulties together, the } \\
\text { rents were reduced and would be adjusted gradually after the control is lifted. }\end{array}$ \\
\hline 4 & Increase in expenses & $\begin{array}{l}\text { The government waived the rent for the epidemic prevention, but the park rent } \\
\text { was not included, so it cannot be waived. } \\
\text { The expenses increased due to the increase of equipment purchase and manpower } \\
\text { control for epidemic prevention. }\end{array}$ \\
\hline
\end{tabular}

Table 9. Response strategies of Huashan 1914 Creative Park in the post-epidemic era

\begin{tabular}{|c|c|c|}
\hline Item & Principle & Description \\
\hline 1 & $\begin{array}{l}\text { Exhibition } \\
\text { extension }\end{array}$ & $\begin{array}{l}\text { Large-scale exhibitions were delayed, and the whole event exploded in the } \\
\text { post-epidemic era. } \\
\text { Some events have been changed to outdoor performances and exhibitions }\end{array}$ \\
\hline 2 & Limited number of visitors & $\begin{array}{l}\text { The number of people was limited, and the distance was enlarged in compliance with } \\
\text { the epidemic prevention regulations. }\end{array}$ \\
\hline 3 & $\begin{array}{l}\text { Development } \\
\text { cooperation units }\end{array}$ & Schools, associations, etc., took the time to hold closed exhibitions and presentations. \\
\hline 4 & $\begin{array}{l}\text { Planning to create } \\
\text { customer data }\end{array}$ & $\begin{array}{l}\text { In the past, the number of visitors was so high that it was not necessary to manage the } \\
\text { membership customers. } \\
\text { In the post-epidemic period, there is a need to take advantage of the opportunity to } \\
\text { accelerate membership recruitment and file development. }\end{array}$ \\
\hline 5 & Park maintenance & Use the time to refurbish the facilities to bring in new business opportunities. \\
\hline
\end{tabular}




\subsection{Creative Brands Interview Compilation}

\subsubsection{Relationship of Creative Branding to the Creator's Expertise or Profession}

During the interviews, we found that 5 of the brand creators started their own business because of their original job or expertise, and they were engaged in developing related products. Only STRING MAN and Yoyo hand were engaged in creation not related to their original work, but both of them started their business out of their interest or love. Others like Ren Jhong Ren, who has been in the design field since he was a student; Lighthouse and January 1st, who are both from related fields; and Mr. Chen of CHANCE, who was a chef before. Although people are not born to be Kings and Generals, if you start a business with relevant experience, you may have a better chance of success.

\subsubsection{Considerations for Creative Brands Choosing a Creative Bazaar}

During the interview, all creative brands mentioned this factor, and six of them mentioned the main consideration when choosing a creative market in their first answer, except for Yoyo hand, who put it in the second place. This shows that the organizer of the creative market is a factor that creative brands attach great importance to. In the interview, the researcher observed that most of the entrepreneurs mentioned that the responsible organizer would assist in the location, cost, and advertising so that the brands participating in the creative market would be less likely to fail or lose money.

\subsubsection{Type of Venue}

The higher the brand recognition, the more requirements for the venue. Because of the weather, if the venue is outdoor in summer, it is easy to cancel the event due to high temperature, sudden heavy rain or the products are scrapped due to rain. For example, the ISHANDS International Creative Market, with its fixed dates and high traffic, is best held in an indoor venue to ensure quality and schedule. Most creative brand owners would prefer an indoor venue. Researchers have observed that the weather temperature and the direction of sunlight do affect the flow of people and the time people spent in front of the brand stall.

Whether or not the organizers of the Creative Market provide equipment does not affect the willingness of brands to participate, which was mainly mentioned by CHANCE and January $1^{\text {st }}$. in the food category. CHANCE explained that the food needs sufficient electricity to ensure safety and hygiene, while January ${ }^{\text {st }}$ said as it's too heavy to carry tables and chairs, it is good to have equipment provided. The creators of the other brands mainly said that it was best to have them, but if not, they would prepare on their own. Equipment is not the main consideration

\subsubsection{Other Related Issues}

Creative brand operators are concerned about having someone to respond to and handle problems, rather than leaving their creative brands to fend for themselves at the market. Advertising, location, and cost are multi-faceted, and they would understand before they participate in the market. A good location would direct high traffic but also be more expensive, so it is not a consideration for creative brands to participate in a general creative market unless the cost exceeds the market rate. Another piece of advice for new brands who want to enter creative bazaars is what Yoyo hand mentioned: "If you are interested in a location for a creative bazaar and observe that it fits your target audience, then keep an eye out for news about the bazaar in that location and sign up when you have the chance." This way you can find out whether your brand positioning matches the actual one, and then the market's organizer would not be the main consideration, and you would find a creative market that suits you by trying more and more.

\subsubsection{Impact of the Epidemic}

Creative brands were affected across the board, regardless of their category. In particular, the brands that rely more on creative markets, the more severely they will be affected. The impact was especially severe for handcrafted food brands, due to controls and an open-air environment. However, this method of protecting food safety has remained after the epidemic and would not be changed just because the epidemic is slightly under control.

\subsubsection{Practices in Response to the Epidemic and Post-Epidemic Era}

In the face of the epidemic, everyone is accelerating the use of the Internet, such as the establishment of e-commerce platforms, shopping malls, product listings, etc., which were already planned and are being accelerated in response to the epidemic and the changes in lifestyle and consumption patterns in the post-epidemic era. In addition, the use of $5 \mathrm{G}$ in contactless transformation business opportunities, webcasting, online teaching, etc. would not be suspended even if the epidemic has passed, but instead would become habitual 
in the post-epidemic era. The performance of e-commerce has maintained growth during and after the epidemic. In addition, the small-scale experience economy is on the rise. In the post-epidemic era, small-scale experiential courses are emerging, where groups of friends can meet to experience hand-made courses and bond with each other in a safe manner. Consignment pop-up stores are also a way to expand the channel, but there are also accompanying costs. Only two people chose this method because it was not very effective when the traffic was low. There are two people who simply don't attend the market because of poor performance, however, there is also one person who attends the market more diligently. As each time the performance was not high, they had to increase their attendance in order to stabilize their income, and at the same time to serve customers and pick up goods at the market. The reason for developing other ways to make a living is that this business cannot ensure income, so they have to do other jobs to support their livelihood. It is a bit sad to mention here, brand management and entrepreneurship really need a little persistence. Several creative brands owners we knew disappeared after the epidemic and were rumored to be back in the workplace. We hope to see them again sometime.

\section{Discussion and Conclusions}

A creative bazaar is an economic activity that combines the intelligence of people to create a series of industrial activities, including creative branding, curatorial planning, venue management, advertising and promoting consumption based on customers' love. The design of cultural and creative goods focuses on the combination of innovation and craftsmanship, conveying the value of the creator, creating a sense of empathy, and establishing a connection between goods, services, and consumers, which is similar to building a brand, and the creative market itself is a brand. The "cultural and creative industry" combines creation, production, and commercial content, and at the same time has the characteristics of both cultural assets and cultural concepts, which is considered an innovative industry. Many experts and scholars believe that after the information industry, the cultural and creative industry is the most important economic driver of the future.

As the old saying goes, "God helps those who help themselves". Taiwan experienced the painful lesson of SARS 19 years ago and started to prepare the related public health plan, so that Taiwan could be a piece of safe land when the world was facing the serious threat of COVID-19, and maintained its economic activities, national life, health education, etc. as usual, and even the economic growth at a high level. The creative market industry was also the industry that was severely affected in the early stages of the outbreak. Although the overall epidemic has not yet passed, and no one expects another epidemic or a new one, from this epidemic, we need to find strategies for transformation in the post-epidemic era. Many of the habits of life, consumer behavior, economic activities, and industrial chains in the post-epidemic era may never be the same as they were before the epidemic. The post-epidemic era is opportune to review the quality of the creative market and its response strategies:

(1) Curators should examine the impact of the epidemic on their creative marketplaces and understanding the priority of brand operators' demand for creative markets. Only by finding out the key factors of success and the value of consumer demands for their creative markets and creating a win-win-win solution can the creative market grow steadily in an environment where there are varying qualities of markets. Creative bazaar and creative brands should first discuss the original aspiration of innovative design and the concept of creative bazaar planning, to take the advantage of a face-to-face meeting with consumers in the bazaar to express the value concept behind the more innovative design, handicraft skills, etc., so that consumers understand why the value of these goods rather than care about the price. Instead of focusing on the CP value, we need to help customers experience the value.

(2) In the post-epidemic era, creative bazaars should take the opportunity to make appropriate transformations and screen out brands that are truly engaged in innovative creation, so that products that are too similar, fake brands that are wholesale, and products that are priced indiscriminately can be withdrawn from the market. In addition, creative bazaars should follow the example of Japan to promote the certification of creative creations by private associations, such as street performers, chefs, laborers, etc. The market activities are also needed grading according to the exhibition so that consumers and brand operators can have a basic understanding of the difference.

(3) Focus on the operation of the main customers, take advantage of the government's industrial transformation subsidies, and leverage network technology to establish the main customer data and develop online shopping, etc., to address the uncertainty in the number of visitors in an open-air creative market, dependence on the venue foot traffic, creative brands soliciting customers and online information disclosure, and promote customers to leave an online footprint.

(4) Propose to amend the Cultural and Creative Industries Law better to better meet the needs and subsidies 
applications, while continuing the competitiveness and survival of the creative bazaar industry, improving the quality of life and art appreciation of the nation, increasing the success rate of start-up businesses in the cultural and creative industry, and avoiding the ineffective waste of resources.

Creative bazaars have been developing in Taiwan since 2006 and are already a very popular and even mature industry. However, the regulations and the positioning of the industry are not clear, so when facing market challenges, they are easily ignored or cannot gain effective support. It is good to see that in this economic revitalization program, the Ministry of Culture has included creative bazaars in the applicable category of Art Fun Voucher. From the interviews, we can find out the needs and considerations of all parties in the creative bazaar industry, so that the whole industry can move forward in a good direction and make the public willing to spend money to support Taiwan's creative industry. There is a need to improve the problem that existing creative bazaar products are too similar and wholesale in case of challenges in the future. Whether each creative bazaar has its characteristics to attract consumers, as well as the classification and the positioning of the creative bazaar is very important. While Asian countries around us have made every effort to support the creative industry, how to get rid of the tangle and move forward depends on the industry, government, and academia to put aside their preconceptions and create a good future for Taiwan's creative market industry.

\section{Acknowledgements}

This research is supported by the National Chin-Yi University of Technology, Taiwan, R.O.C. (under Project: Discussion on Integrating Industry Experts' Collaborative Teaching, Institutional Visits, and Issue method to Improve Student Learning Outcomes).

\section{References}

Chen Y. (1995). Case study method. Dictionary of Library Science and Information Science. Taipei: Hanmei Publishing Co.

Chou, Y. (2009). Contemporary trend of emotive experiential design-A case study of handicrafts (Unpublished master's thesis). National Taichung University of Science and Technology, Taichung, R.O.C.

Davies, R., \& Sigthorsson, G. (2013). Introducing the creative industries-From theory to practice. London: SAGE Publications Ltd.

Department of Statistics, Ministry of Culture R.O.C. (2021). Taiwan cultural \& creative industries annual report. Retrieved from https://stat.moc.gov.tw/Research.aspx?type $=5$

Eisenhardt, K. (1989). Building theories from case study research. Academy of Management Review, 14(4), 532-550. https://doi.org/10.2307/258557

Herzog, T. (1996). Research methods and data analysis in the social sciences. London: Pearson.

Kotler, P., \& Armstrong, G. (2017). Principle of marketing (17th ed.). Pearson Education Inc. Prentice Hall.

Lee, C. (2009). In shaping the creative milieu: A multiple-case study of fashion market organizers in Taiwan (Unpublished master's thesis). National Taiwan Normal University, Taipei, R.O.C.

Luo, Y. (2008). The development of contemporary fashion market and consumption culture in Taiwan-Focusing on the "CAMPO Art Festival." Visual Arts Forum, 3, 70-88. https://doi.org/10.29523/VAF.200807.0004

Ministry of Culture R.O.C. (2021). Measures for the relief and revitalization of industries and businesses affected by severe special contagious pneumonia and operating difficulties. Retrieved from https://www.moc.gov.tw/content_434.html

Pan, G. (2015). Taiwan made a fatal mistake - regards culture as the core of creativity. Retrieved from https://www.gvm.com.tw/article/28749

Patton, M. (2002). Qualitative evaluation and research methods (3rd ed.). Thousand Oaks, CA: Sage.

Soule, A. (2017). The creative family: How to encourage imagination and nurture family connections. Boulder: Roost Books.

Wang, I. (2004). Fashion market. Taipei: Gardencity Publishers.

Wang, P. (2014). A study of key success factors for cultural and creative industries in Taiwan (Unpublished master's thesis). National Cheng Kung University, Tainan, R.O.C.

Wen, C., \& Yang, K. (2000). Interview survey method. Taipei: Tung Hua Book Co., Ltd.

Yuan F. (2002). Social research methods. Taipei: Wu-Nan Book Inc.

Zhang, Z., Huang, Y., \&Wu, Y. (2019). Discussion on improving the purchase intention of consumers in Taiwan's cultural and creative markets-Taking creative markets in Taipei as an example. Journal of Graphic Communication Arts, 239 -258. https://doi.org/10.29886/NTUADGCA 


\section{Copyrights}

Copyright for this article is retained by the author(s), with first publication rights granted to the journal.

This is an open-access article distributed under the terms and conditions of the Creative Commons Attribution license (http://creativecommons.org/licenses/by/4.0/). 